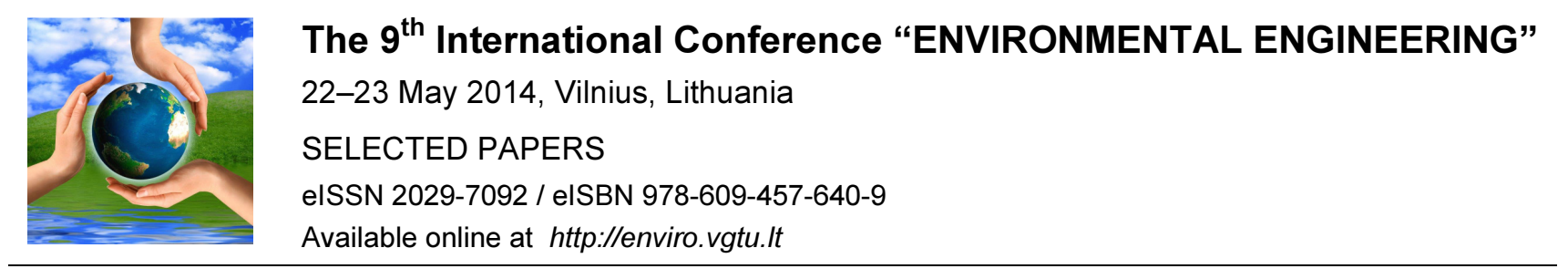

Section: Technologies of Geodesy and Cadastre

\title{
Analysis of the Impact of Virtual Reference Stations on Static Positioning
}

\author{
Jakub Kalita ${ }^{\mathrm{a}}$, Zofia Rzepecka ${ }^{\mathrm{b}}$ \\ ${ }^{a}$ Koszalin University of Technology, Sniadeckich 2, Koszalin 75-453, Poland \\ ${ }^{b}$ University of Warmia and Mazury, Prawochenskiego 15, Olsztyn 10-720, Poland
}

\begin{abstract}
The aim of this work was to study the influence of artificial GPS observations, obtained by the Virtual Reference Station (VRS) technique on static positioning results in post-processing mode. The accuracy of positioning using VRS stations was investigated. Precise static determinations were analyzed. The VRS data were obtained from the POZGEO-D service of the ASG-EUPOS network. Test computations were performed with Leica GeoOffice and Ashtech Office Suite GPS software. The discussion of results is preceded by a general description of the VRS method and algorithms. The bulk of the paper is of practical character, it derives some advices to the users of active permanent networks like the EUPOS system. The last part of the paper is devoted to analyses of the virtual observations.
\end{abstract}

Keywords: Virtual Reference Station; VRS; physical reference station; ASG-EUPOS network; static positioning.

\section{Introduction}

It is well-known that GNSS techniques, both static and kinematic, can be effectively used for deformation monitoring. However, less discussion has beendevoted to the use of the Virtual Reference Station (VRS) concept.Originally, the purpose of the VRS concept was to apply the Network Real Time Kinematic (NRTK) technique, sometimes called RTN, by transferring network corrections to a receiver that uses versions 2.x of the Radio Technical Commission for Maritime Services (RTCM) standard. The application of VRS for GPS-based positioning using post-processed static calculations is analyzed in this paper.

The authors of the paper sought to answer the following questions:

- Do VRSs constitute a good reference system for geodetic determinations?

- What is the difference betweenelaborating GPS measurement data directly from a physical reference station and from a

VRS set up very close to the point with an unknown position when using ordinary commercial GNSS processing software?

- How much do VRS observations correspond to observations gathered by a physical station situated at the location of VRS generation and how does this influence the results of computation?

- Do additional VRSs reinforce the geometry of the system and improve positioning quality?

The paper starts with a brief theoretical basis forcreating artificial observations, then proceeds to present the results of the studies. The overall conclusions, together with a summary and attempts to addressthe questions listed above, are presented in the final section.

\subsection{ReviewofVRSalgorithms}

There is a baseline-length limitation when performing Real-Time Kinematic (RTK) measurements using a single reference station. Signal atmospheric propagation errors become less spatially correlated between receivers as the baseline's length increases. The threshold distance is thought to be at the level of 10 to $20 \mathrm{~km} \mathrm{[1-3].} \mathrm{Networks} \mathrm{of} \mathrm{reference} \mathrm{stations} \mathrm{can} \mathrm{be}$ used to overcome this limitation, since by applying them, it is possible to mitigate the effects of atmospheric biases and orbital errors which cause the degradation of RTK positioning accuracy and precision.

Corresponding author: Zofia Rzepecka. E-mail address: zofia.rzepecka@uwm.edu.pl

http://dx.doi.org/10.3846/enviro.2014.214

(C) 2014 The Authors. Published by VGTU Press. This is an open-access article distributed under the terms of the Creative Commons Attribution License, which permits unrestricted use, distribution, and reproduction in any medium, provided the original author and source are credited. 
Methodologies for NRTK are used to interpolate the atmospheric biases from reference stations to user location. They can be grouped into methods that use non-physical reference stations (Virtual Reference Station, VRS; Pseudo-Reference Station, PRS; individualized Master Auxiliary Correctons, iMAX) and those that broadcast corrections and raw reference station observations to users (Master Auxiliary Convept, MAX; Flächenkorrekturparameter, FKP)[4].

The most prevalent methodologies connected with NRTK are VRS and MAC. They were compared from both the user and reference station operator's perspectives by Janssen [3].

VRS, a trademark of Trimble Inc., is a technique that generates artificial measurements for a particular location. These data, in addition to delays connected with propagation of the signal from a satellite to virtual receiver, incorporate propagation biases that are estimated basing on the network. The main advantage of VRS is that it does not need algorithmic modification in the receiver as VRS simulates the real reference station.

First, the rover determines its approximate position and sends it to the network, which generates a Virtual Reference Station for that position. The procedure covers the following: resolution of integer ambiguities for reference stations, determination of empirical distance-dependent errors, and interpolating corresponding delays to VRS location [1-2, 5]. The above is possible assuming that the coordinates of reference stations are known.

Afterwards, the artificial measurements are sent to the rover. The above procedure can be executed iteratively to reducethe distance between the rover and virtual reference stations' positions. The code measurement model is analogous except that the phase measurement is replaced by code measurement and the ionosphere error is of a reverse sign.

It is not useful to transfer purely station-dependent errors such as: noise, multipath and errors connected with the antenna phase center, to theVRS, as they are uncorrelated between stations [6]. After integer-ambiguities have been resolved, delays connected with both ionosphere and troposphere can be determined in the form of either zero-difference (ZD), single difference (SD) or double difference (DD) measurements. Ionospheric delay is a dispersive error source and can be estimated or eliminated by using a linear combination of measurements on different frequencies while tropospheric delay and orbit errors are non-dispersive.

The interpolation methods used to transfer corrections to the VRS location can be grouped into either geostatistical ordeterministic methods. Methods assigned to the former are: Ordinary Kriging Method (OK), and Least Squares Collocation Method (LSC). For the latter, we may include: Linear Combination Method (LC), Linear Interpolation Method (LI), Low-order Surface Method (LS), and Multi-quadric Surface Fitting Method (MSF).Together with theanalysis onpositioning quality this classification was proposedby Al-Shaery et al. [1].

The accuracy of positioning based on VRS can be assessed by means of the generated observations quality. In most cases, the baseline length between the simulated reference station and the rover is very short, and it can thus be assumed that no additional impact is generated. However, it is important that the height for the VRS in particular should be on the same level as that for the rover.Using a different troposphere model in the network than in the rover can cause errors of 0.2 millimeters per every 10 meters of difference in height [7].The claimed performance of VRS is on the level of $5 \mathrm{~cm}$ for baselines at up to $35 \mathrm{~km}$. For the height component it is 1.5 to 2 times greater.

According to recent analysis, the length ofRTK baselines can be extended to at least $50 \mathrm{~km}$ when using VRS technology [8]. A horizontal accuracy of less than $2 \mathrm{~cm}, 2.4 \mathrm{~cm}$ and $4.4 \mathrm{~cm}$ over $20.7 \mathrm{~km}, 44.8 \mathrm{~km}$ and $62.5 \mathrm{~km}$ length baseline, respectively, can be achieved [9]. For the Swiss networks, where the maximum length to thereference station is $30 \mathrm{~km}$, an accuracy of 2 and $4 \mathrm{~cm}$ for the horizontal and vertical components, respectively, is claimed [7]. Results based on theSingapore prototype network infrastructure, where the distance between reference stations is at the level of $20 \mathrm{~km}$, have confirmed that VRS RTK positioning within $3 \mathrm{~cm}$ in horizontal and $5 \mathrm{~cm}$ in vertical positions can be achieved [2].

Key issues of NRTK and VRS are the precision of the distance-dependent errors affecting GNSS signals at the reference stations and the accuracy of corrections' interpolation to the location of VRS [1]. This has the biggest influence on the accuracy of positioning whenusing the technique.

\section{Methods and results}

\subsection{Description of the network}

The analysis was based on an experiment performed in the region between Koszalin (ASG-EUPOS station KOSZ) and Slupsk (ASG-EUPOS station REDZ) on March 20, 2013. Computations were carried out using the LGO (Leica GeoSystems, 2009) and AOS software, v. 2.1 (Magellan, 1999). The physical and virtual reference station observations were taken from the POZGEO-D service of the ASG-EUPOS system, the Polish section of the European Position Determination System (EUPOS), where Trimble VRS ${ }^{3}$ Net (v. 1.4.1) is used for VRS generation. In 2011, it replaced GPSNet/RTKNet software. A summary of the antennas and receivers used is presented in Table 1. An outline of the measured physical stations is given in Figure 1. KOSZ, REDZ and SZE2 are the 3 nearest ASG-EUPOS stations surrounding the terrain of interest. Stations GORZ, KARN, RYSZ, SMRD, TYCH were measured specially for this experiment, they are referred to as unknown stations throughout the paper.

Additionally, 23 virtual stations were used in the experiment, one VRS within one hundred meters off each station KOSZ, REDZ and SZE2 (see Fig. 1) with four VRSs around each of the unknown stations. 
Table 1. Receivers and antennas used in the experiment.

\begin{tabular}{lll}
\hline Point & Receiver & Antenna \\
\hline 3 ASG-EUPOS and all VRS stations & Trimble NETRS & TRM41249.00 TZG or TRM55971 TZG \\
5 measured stations & Leica 1200 & LEIAX1202GG or LEIGS08 \\
\hline
\end{tabular}

The RINEXobservation files generated for virtual stations, contain information about which ASG-EUPOS physical station was used as the basestation (see Section 1). It was found that VRSs around TYCH were derived on the basis of the REDZ station, while all the other VRSs near the remaining unknown stations were created on the basis of the KOSZ station.

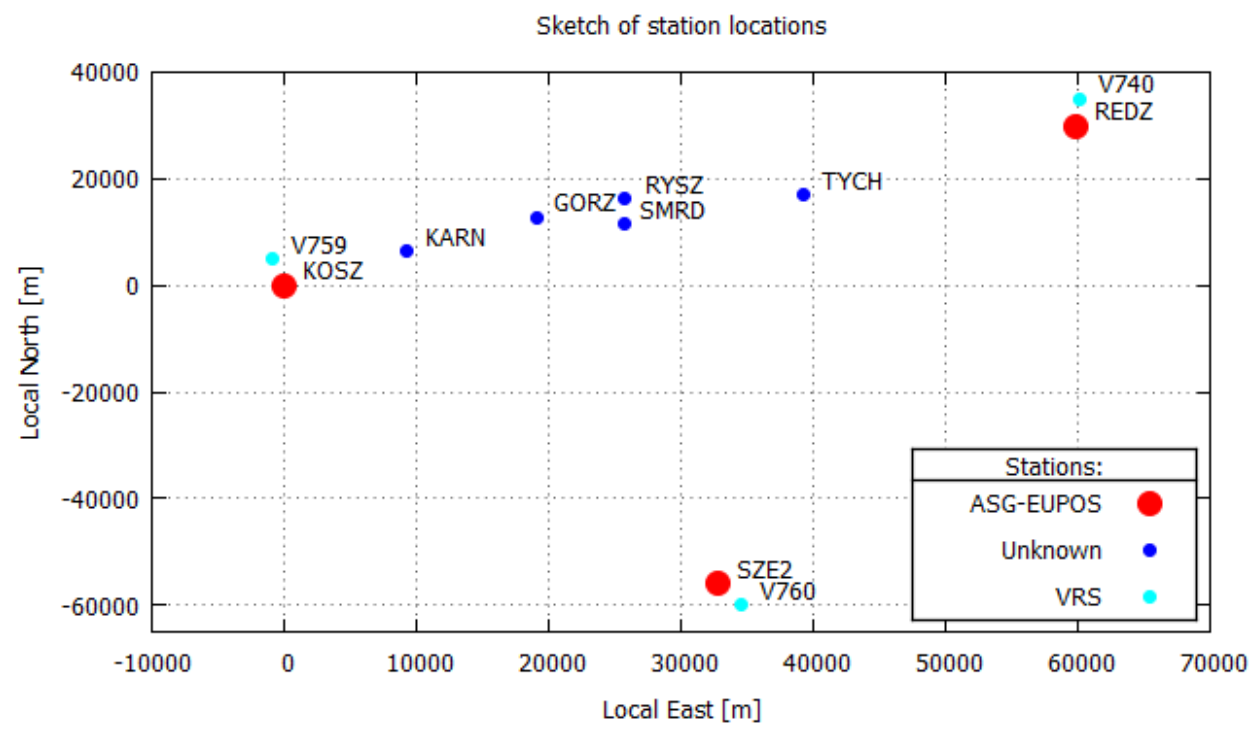

Fig. 1. The geometry of the stations measured: 8 real stations ( 3 ASG-EUPOS and 5 measured) and $3 \mathrm{VRSs}$ (shifted to be distinguishable in the scale of the plot)

\subsection{Analysisof static session results and reference solution selection}

All the baselines between physical stations were computed (8 stations, 28 baselines) using both the LGO and AOS packages.The AOS results were worse than those obtained using the LGO. Not all AOS's solutions were acceptable, the standard deviation values sDX, sDY, sDZ of part of the vectors exceeded $50 \mathrm{~cm}$ (GORZ-SMRS, GORZ-TYCH, KARNRYSZ, REDZ-SMRD, REDZ-TYCH, SMRD-TYCH). Prior to the strict adjustment, radial determinations obtained from the three physical reference stations were compared. From these comparison, which was conducted in a local ENU system with KOSZ taken as its origin, it is obvious that results obtained for the REDZ station are burdened with gross errors and that the best agreement is between positions obtained from KOSZ and SZE2 stations. Some variants of the adjustment were investigated (like all fixed vectors, all the computed vectors, adjustment without the REDZ station). The best results were obtained in the variant without the REDZ station. On the other hand, using vectors computed with LGO (with all physical stations), the results were betterand thus the LGO-based solution is admitted as a reference one for further studies. The residuals in this adjustment as well as the final accuracy estimation is on the level of single millimeters.

\section{Analysis of the effect of VRS application in network elaboration}

\subsection{Comparisonof vectorsoriginating from physical and virtual stations}

In this section, the vectors of type KOSZ-KARN versus V759-KARN (similarly for the other unknown stations, see Fig. 1) are analysed. Since the pairs of stations KOSZ together with V759, SZE2 together with V760 and REDZ together with V740 are located very close to each other, the determinations of the unknowns on the basis of vectors starting from KOSZ and from V759, from SZE2 and from V760, from REDZ and from V740 should be similar. The comparisons are given in Tables 2 and 3. It is seen that for the LGO software, the solutions obtained from physical reference and close VRS stations are almost the same, the differences exceed $1 \mathrm{~cm}$ only in the case of vectors SZE2-RYSZ and V760-RYSZ.

For the vector SZE2-RYSZ it is seen that this radial determination is the weakest and it differs from the reference solution by $-0.014 \mathrm{~m},-0.048 \mathrm{~m}, 0.020 \mathrm{~m}$. The solution obtained from the associated virtual station is closer to the reference values, thus it may be regarded as better. In the case of AOS software, solutions obtained for KOSZ and V759, and for SZE2 and V760 conformto singlemillimeters. For the station REDZ, there were apparent gross errors for vectors to SMRD and TYCH, other vectors with REDZ station also were not very good. But when computed from V740 - the solutions are 
much closer to the reference solution, differences in $\Delta \mathrm{E}$ and $\Delta \mathrm{N}$ are within $2 \mathrm{~cm}$, in the Up component the differences in the vectors of interest are of systematic character and equal to about $-4 \mathrm{~cm}$. However, they are not burdened with gross errors. Thus, it can be stated that when the solution from physical station is of poor quality, the solution from virtual station can be used instead of it.

Table 2. Radial determinations from physical and virtual stations - LGO software

\begin{tabular}{|c|c|c|c|c|c|c|c|c|c|}
\hline \multirow{2}{*}{$\begin{array}{l}\text { Unknown } \\
\text { station }\end{array}$} & \multicolumn{3}{|c|}{ From KOSZ - REF_SOL } & \multicolumn{3}{|c|}{ From V759-REF_SOL } & \multicolumn{3}{|c|}{ From KOSZ - from v759 } \\
\hline & $\Delta \mathrm{E}[\mathrm{m}]$ & $\Delta \mathrm{N}[\mathrm{m}]$ & $\Delta \mathrm{U}[\mathrm{m}]$ & $\Delta \mathrm{E}[\mathrm{m}]$ & $\Delta \mathrm{N}[\mathrm{m}]$ & $\Delta \mathrm{U}[\mathrm{m}]$ & $\Delta \mathrm{E}[\mathrm{m}]$ & $\Delta \mathrm{N}[\mathrm{m}]$ & $\Delta \mathrm{U}[\mathrm{m}]$ \\
\hline GORZ & 0,005 & 0,005 & 0,016 & 0,003 & 0,001 & 0,017 & 0,002 & 0,004 & $-0,001$ \\
\hline KARN & 0,004 & 0,005 & 0,011 & 0,002 & 0,001 & 0,013 & 0,002 & 0,004 & $-0,002$ \\
\hline RYSZ & 0,005 & 0,005 & 0,022 & 0,003 & 0,001 & 0,022 & 0,002 & 0,004 & 0,000 \\
\hline SMRD & 0,005 & 0,006 & 0,021 & 0,002 & 0,002 & 0,022 & 0,002 & 0,004 & $-0,001$ \\
\hline TYCH & 0,006 & $-0,003$ & 0,026 & 0,004 & $-0,007$ & 0,028 & 0,002 & 0,004 & $-0,002$ \\
\hline Unknown & \multicolumn{3}{|c|}{ From REDZ - REF_SOL } & \multicolumn{3}{|c|}{ From V740-REF_SOL } & \multicolumn{3}{|c|}{ From REDZ - from v740 } \\
\hline station & $\Delta \mathrm{E}[\mathrm{m}]$ & $\Delta \mathrm{N}[\mathrm{m}]$ & $\Delta \mathrm{U}[\mathrm{m}]$ & $\Delta \mathrm{E}[\mathrm{m}]$ & $\Delta \mathrm{N}[\mathrm{m}]$ & $\Delta \mathrm{U}[\mathrm{m}]$ & $\Delta \mathrm{E}[\mathrm{m}]$ & $\Delta \mathrm{N}[\mathrm{m}]$ & $\Delta \mathrm{U}[\mathrm{m}]$ \\
\hline GORZ & $-0,011$ & 0,012 & 0,010 & $-0,014$ & 0,008 & 0,011 & 0,002 & 0,003 & $-0,001$ \\
\hline KARN & 0,023 & 0,001 & $-0,015$ & 0,015 & $-0,001$ & $-0,018$ & 0,007 & 0,002 & 0,004 \\
\hline RYSZ & $-0,020$ & 0,023 & $-0,002$ & $-0,022$ & 0,019 & $-0,003$ & 0,003 & 0,004 & 0,001 \\
\hline SMRD & 0,009 & 0,012 & $-0,002$ & 0,007 & 0,008 & $-0,002$ & 0,002 & 0,004 & 0,000 \\
\hline TYCH & $-0,008$ & 0,015 & 0,001 & $-0,011$ & 0,011 & 0,001 & 0,002 & 0,004 & 0,000 \\
\hline \multirow{2}{*}{$\begin{array}{l}\text { Unknown } \\
\text { station }\end{array}$} & \multicolumn{3}{|c|}{ From SZE2 - REF_SOL } & \multicolumn{3}{|c|}{ From V760-REF_SOL } & \multicolumn{3}{|c|}{ From SZE2 - from v760 } \\
\hline & $\Delta \mathrm{E}[\mathrm{m}]$ & $\Delta \mathrm{N}[\mathrm{m}]$ & $\Delta \mathrm{U}[\mathrm{m}]$ & $\Delta \mathrm{E}[\mathrm{m}]$ & $\Delta \mathrm{N}[\mathrm{m}]$ & $\Delta \mathrm{U}[\mathrm{m}]$ & $\Delta \mathrm{E}[\mathrm{m}]$ & $\Delta \mathrm{N}[\mathrm{m}]$ & $\Delta \mathrm{U}[\mathrm{m}]$ \\
\hline GORZ & $-0,020$ & $-0,008$ & 0,007 & $-0,025$ & $-0,006$ & 0,017 & 0,005 & $-0,002$ & $-0,010$ \\
\hline KARN & $-0,002$ & $-0,005$ & $-0,004$ & $-0,007$ & $-0,003$ & 0,006 & 0,005 & $-0,002$ & $-0,010$ \\
\hline RYSZ & $-0,014$ & $-0,048$ & 0,020 & 0,000 & $-0,021$ & 0,030 & $-0,014$ & $-0,027$ & $-0,010$ \\
\hline SMRD & 0,001 & $-0,008$ & $-0,007$ & $-0,005$ & $-0,006$ & 0,003 & 0,005 & $-0,002$ & $-0,010$ \\
\hline TYCH & $-0,017$ & $-0,006$ & $-0,005$ & $-0,022$ & $-0,004$ & 0,005 & 0,005 & $-0,002$ & $-0,010$ \\
\hline
\end{tabular}

Table 3. Radial determinations from physical and virtual stations - AOS software

\begin{tabular}{|c|c|c|c|c|c|c|c|c|c|}
\hline \multirow{2}{*}{$\begin{array}{c}\text { Unknown } \\
\text { station }\end{array}$} & \multicolumn{3}{|c|}{ From KOSZ - REF_SOL } & \multicolumn{3}{|c|}{ From V759-REF_SOL } & \multicolumn{3}{|c|}{ From KOSZ - from v759 } \\
\hline & $\Delta \mathrm{E}[\mathrm{m}]$ & $\Delta \mathrm{N}[\mathrm{m}]$ & $\Delta \mathrm{U}[\mathrm{m}]$ & $\Delta \mathrm{E}[\mathrm{m}]$ & $\Delta \mathrm{N}[\mathrm{m}]$ & $\Delta \mathrm{U}[\mathrm{m}]$ & $\Delta \mathrm{E}[\mathrm{m}]$ & $\Delta \mathrm{N}[\mathrm{m}]$ & $\Delta \mathrm{U}[\mathrm{m}]$ \\
\hline GORZ & $-0,0258$ & $-0,0162$ & 0,02058 & $-0,0284$ & $-0,018$ & 0,02158 & $-0,0026$ & $-0,0018$ & 0,001 \\
\hline KARN & $-0,008$ & $-0,0078$ & 0,01424 & $-0,0114$ & $-0,0102$ & 0,01224 & $-0,0034$ & $-0,0024$ & $-0,002$ \\
\hline RYSZ & $-0,0344$ & $-0,0273$ & 0,02772 & $-0,037$ & $-0,03$ & 0,02472 & $-0,0026$ & $-0,0027$ & $-0,003$ \\
\hline SMRD & 0,0158 & $-0,0006$ & 0,01796 & 0,0122 & $-0,0033$ & 0,01596 & $-0,0036$ & $-0,0027$ & $-0,002$ \\
\hline TYCH & 0,0104 & $-0,0072$ & 0,01766 & 0,0068 & $-0,0096$ & 0,01566 & $-0,0036$ & $-0,0024$ & $-0,002$ \\
\hline Unknown & \multicolumn{3}{|c|}{ From REDZ - REF_SOL } & \multicolumn{3}{|c|}{ From V740 - REF_SOL } & \multicolumn{3}{|c|}{ From REDZ - from v740 } \\
\hline station & $\Delta \mathrm{E}[\mathrm{m}]$ & $\Delta \mathrm{N}[\mathrm{m}]$ & $\Delta \mathrm{U}[\mathrm{m}]$ & $\Delta \mathrm{E}[\mathrm{m}]$ & $\Delta \mathrm{N}[\mathrm{m}]$ & $\Delta \mathrm{U}[\mathrm{m}]$ & $\Delta \mathrm{E}[\mathrm{m}]$ & $\Delta \mathrm{N}[\mathrm{m}]$ & $\Delta \mathrm{U}[\mathrm{m}]$ \\
\hline GORZ & 0,0130 & $-0,0057$ & $-0,0414$ & 0,0114 & $-0,0096$ & $-0,0384$ & $-0,0016$ & $-0,0039$ & 0,0030 \\
\hline KARN & $-0,0074$ & 0,0444 & 0,0112 & 0,0194 & $-0,003$ & $-0,0388$ & 0,0268 & $-0,0474$ & $-0,0500$ \\
\hline RYSZ & 0,0748 & 0,006 & $-0,0323$ & 0,0124 & $-0,0084$ & $-0,0493$ & $-0,0624$ & $-0,0144$ & $-0,0170$ \\
\hline SMRD & $-5,014$ & 4,3167 & 0,46096 & 0,0174 & 0,0024 & $-0,0390$ & 5,0314 & $-4,3143$ & $-0,5000$ \\
\hline TYCH & 1,2186 & $-1,7952$ & 3,40966 & 0,0108 & $-0,0054$ & $-0,0373$ & $-1,2078$ & 1,7898 & $-3,4470$ \\
\hline Unknown & \multicolumn{3}{|c|}{ From SZE2 - REF_SOL } & \multicolumn{3}{|c|}{ From V760 - REF_SOL } & \multicolumn{3}{|c|}{ From SZE2 - from v760 } \\
\hline station & $\Delta \mathrm{E}[\mathrm{m}]$ & $\Delta \mathrm{N}[\mathrm{m}]$ & $\Delta \mathrm{U}[\mathrm{m}]$ & $\Delta \mathrm{E}[\mathrm{m}]$ & $\Delta \mathrm{N}[\mathrm{m}]$ & $\Delta \mathrm{U}[\mathrm{m}]$ & $\Delta \mathrm{E}[\mathrm{m}]$ & $\Delta \mathrm{N}[\mathrm{m}]$ & $\Delta \mathrm{U}[\mathrm{m}]$ \\
\hline GORZ & $-0,0084$ & $-0,0165$ & 0,00558 & $-0,0054$ & $-0,0228$ & 0,0036 & 0,003 & $-0,0063$ & $-0,002$ \\
\hline KARN & $-0,0002$ & $-0,0135$ & 0,01324 & 0,0028 & $-0,0195$ & 0,0102 & 0,003 & $-0,006$ & $-0,003$ \\
\hline RYSZ & $-0,0056$ & $-0,0234$ & 0,00272 & $-0,0024$ & $-0,0261$ & $-0,0033$ & 0,0032 & $-0,0027$ & $-0,006$ \\
\hline SMRD & $-0,0016$ & $-0,0105$ & 0,01296 & 0,0008 & $-0,0156$ & 0,0100 & 0,0024 & $-0,0051$ & $-0,003$ \\
\hline TYCH & $-0,0052$ & $-0,0177$ & 0,01366 & $-0,0028$ & $-0,0231$ & 0,0100 & 0,0024 & $-0,0054$ & $-0,004$ \\
\hline
\end{tabular}

\subsection{Replacement of physical ASG-EUPOS station with VRSs}

The reference solution was obtained from adjustment of the whole network tied to the 3 physical reference stations. Such a configuration could be computed using the LGO software. In case of the AOS - only two physical reference stations could be used, since using the REDZ station deteriorated the results. Thus the whole solution in AOS, obtained from only two physical reference station is probably weaker. Therefore following scenarios of replacing the physical reference stations by VRSs are proposed and analysed:

- 3 VRSs located in proximity to the physical stations are used as fixed known reference

- 3 VRSs located in proximity to unknown stations are used as fixed known reference 
In the former, the virtual stations V740, V759 and V760 have been used. In the latter, the 3 virtual stations chosen were located near TYCH, SMRD and KARN (within about $100 \mathrm{~m}$ ). Both the solutions were compared to the reference solution, resulting in the values given in Tables 4 and 5.

Table 4. Adjustment results with V740, V759 and V760 used as tying points (in proximity of physical stations)

\begin{tabular}{|c|c|c|c|c|c|c|}
\hline \multirow[t]{2}{*}{ Station } & \multicolumn{3}{|c|}{ LGO: 3 far VRS - REF_SOL } & \multicolumn{3}{|c|}{ AOS: 3 far VRS - REF_SOL } \\
\hline & $\Delta \mathrm{E}[\mathrm{m}]$ & $\Delta \mathrm{N}[\mathrm{m}]$ & $\Delta \mathrm{U}[\mathrm{m}]$ & $\Delta \mathrm{E}[\mathrm{m}]$ & $\Delta \mathrm{N}[\mathrm{m}]$ & $\Delta \mathrm{U}[\mathrm{m}]$ \\
\hline GORZ & 0,007 & $-0,004$ & 0,0101 & $-0,004$ & $-0,015$ & $-0,01242$ \\
\hline KARN & 0,003 & $-0,004$ & 0,0077 & $-0,001$ & $-0,010$ & $-0,00076$ \\
\hline RYSZ & 0,007 & $-0,004$ & 0,0101 & $-0,001$ & $-0,016$ & $-0,02328$ \\
\hline SMRD & 0,009 & $-0,005$ & 0,0119 & 0,011 & $-0,005$ & $-0,01204$ \\
\hline TYCH & 0,004 & $-0,004$ & 0,0081 & 0,005 & $-0,013$ & $-0,01234$ \\
\hline
\end{tabular}

Table 5. Adjustment results withVRSs used as tying points (in proximity of unknown stations)

\begin{tabular}{|c|c|c|c|c|c|c|}
\hline \multirow[t]{2}{*}{ Station } & \multicolumn{3}{|c|}{ LGO: 3 close VRS - REF_SOL } & \multicolumn{3}{|c|}{ AOS: 3 close VRS - REF_SOL } \\
\hline & $\Delta \mathrm{E}[\mathrm{m}]$ & $\Delta \mathrm{N}[\mathrm{m}]$ & $\Delta \mathrm{U}[\mathrm{m}]$ & $\Delta \mathrm{E}[\mathrm{m}]$ & $\Delta \mathrm{N}[\mathrm{m}]$ & $\Delta \mathrm{U}[\mathrm{m}]$ \\
\hline GORZ & 0,001 & $-0,003$ & 0,0021 & 0,010 & $-0,004$ & 0,01458 \\
\hline KARN & 0,001 & $-0,003$ & 0,0035 & 0,021 & 0,003 & 0,00524 \\
\hline RYSZ & 0,001 & $-0,003$ & 0,0018 & 0,003 & $-0,013$ & 0,01672 \\
\hline SMRD & 0,003 & $-0,003$ & 0,0023 & 0,003 & $-0,003$ & 0,01796 \\
\hline TYCH & $-0,002$ & $-0,003$ & $-0,0003$ & 0,011 & $-0,008$ & 0,00966 \\
\hline
\end{tabular}

For the LGO software in both the cases the solutions agree very well with the reference coordinates, wherein in case of nearer VRSs the differences from the reference solution do not exceed $5 \mathrm{~mm}$, even for the $\Delta U$ component (see Table 5). For the far VR stations the differences for the $\Delta \mathrm{U}$ component slightly exceed $1 \mathrm{~cm}$. When AOS is concerned, both the solutions are quite good, but still worse thanthe LGO's, the differences are within $2 \mathrm{~cm}$.

\subsection{Determination of the unknown stations from short vectors to the close VRSs}

In close vicinity of each unknown station, four virtual stations were requested (about 100 meters to the North, South, East and West). Each of the unknown station was determined from one of these VRSs in the radial determination using the LGO and AOS. The coordinates were compared with the reference solution (see Fig. 2). The differences obtained from both packages are similar, the biggest dispersion is for the $\Delta \mathrm{U}$ component $(-0.01$ to $+0.027 \mathrm{~m}$ for $\mathrm{LGO}$ and -0.015 to $+0.017 \mathrm{~m}$ for AOS). All the $\Delta \mathrm{E}$ components are positive, while all the $\Delta \mathrm{N}$ components are negative. For AOS package this is the best solution in the sense of agreement with the reference solution.

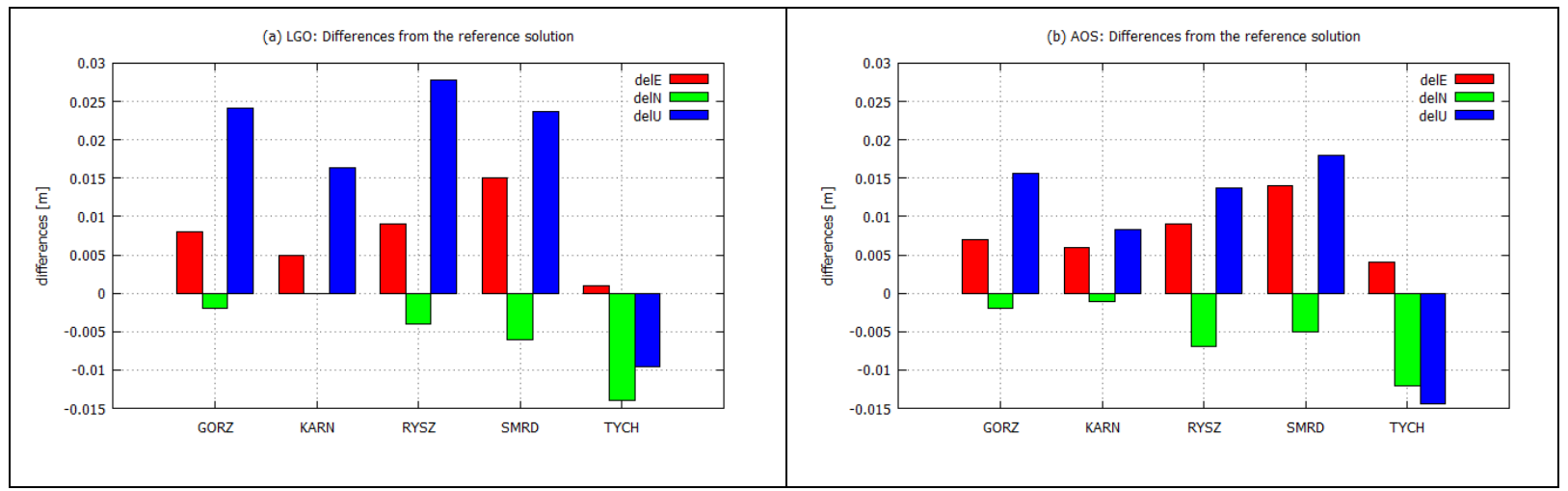

Fig. 2. Differences between the reference solution and the coordinates determined individually from the close VRSs, a) LGO, b) AOS

\subsection{Legitimacy analysis of using more than one close VRS for determination of unknown station coordinates}

Some surveyors practice applying more than one virtual station in proximity of the unknown station.In this analysis, all the unknown points were determined four times - from each VRSs located around it. All these determinations are highly correlated.They are practically the same (as an example, coordinates obtained forKARN station are given in Table 6 . Similar results are observed for other unknown points. When such results would be adjusted, the resulting accuracy estimation would be unreliably good (error ellipses parameters do not exceed $0.1 \mathrm{~mm}$ in any case). For boththe LGO and AOS packages the situation isthe same. 
Table 6. Determinations of the KARN station from the 4 VRSs located around it

\begin{tabular}{cccc}
\hline Baseline & $\mathrm{X}[\mathrm{m}]$ & $\mathrm{Y}[\mathrm{m}]$ & $\mathrm{Z}[\mathrm{m}]$ \\
\hline KARN from V088 & 3582993.1104 & 1050473.3131 & 5153773.2056 \\
KARN from V089 & 3582993.1106 & 1050473.3132 & 5153773.2055 \\
KARN from V090 & 3582993.1105 & 1050473.3133 & 5153773.2056 \\
KARN from V091 & 3582993.1106 & 1050473.3131 & 5153773.2056 \\
\hline
\end{tabular}

\section{Analysis of REDZ-TYCH and V740-TYCH vectors}

Looking through the radial and network solution results (given in Tables 2-5), it can be stated that when the solution is good (fixed ambiguities, high estimated accuracies) the differences between vectors containing and not-containing VRSs are on the level of single millimeters. In some cases the differences reach the level of 2-3 cm, especially for the AOS solutions. But the biggest differences between the "with VRSs" and "without VRSs" have been observed in the case of bad solutions obtained in the AOS software (vectors REDZ-SMRD and REDZ-TYCH versus vectors V740-SMRD and V740-TYCH). It is worth to check what differences are between the observations at physical stations and created for the virtual ones. Since the raw observations contain big systematic components, combinations of L1 and L2 observations were inspected using code and phase observations. All the combinations with code observations are similar for "with VRSs" and "without VRSs". The differences could be observed only for combinations containing the phase data which are sensitive to cycle slips.

For the purpose of this paper the combinations presented in Eqn(1) [6] have been analysed.

$$
\varphi_{A B}^{i j}=\rho_{A B}^{i j} / \lambda+N_{A B}^{i j}+\zeta+\varepsilon
$$

where $\varphi_{A B}^{i j}, \rho_{A B}^{i j}, N_{A B}^{i j}$ are double differenced phase observations, geometrical ranges and integer ambiguities respectively, $\lambda$ is the carrier wavelength, $\zeta$ are the systematic influences containing double differenced ionosphere and troposphere residuals and $\varepsilon$ are the random errors and are assumed to be an unmodelled zero-mean random noise. After putting the known values to the left side, and leaving the unknown terms in the right side one obtains Eqn (2).

$$
\varphi_{A B}^{i j}-\rho_{A B}^{i j} / \lambda=N_{A B}^{i j}+\zeta+\varepsilon
$$

All the terms on the right side are of low variation, except forthe case when a cycle slip occurs.this leads to a sudden jump of the phases' timedifference. Thus inspecting variability of thecombination it is possible to observe thelarge cycle slips and the sum of systematic and random influences. The characteristics of the sampleresults are presentedin Figure 3 and Figure 4. Observations from 11 common satellites were gatheredat stations REDZ, TYCH and generated at V740. The variability of the observation reveals the level of systematic influence and its variability. To see how the random errors behave, it is common to compute the first time differences of double differenced observations (in GNSS nomenclature these are triple differences). Such differences are used to detect cycle slips since all the irregularities of the data are amplified in time differences. The approximate range of changes due to the systematic influences is estimatedto $0.5 \mathrm{~m}$ per about 2 hours in the analysed data.

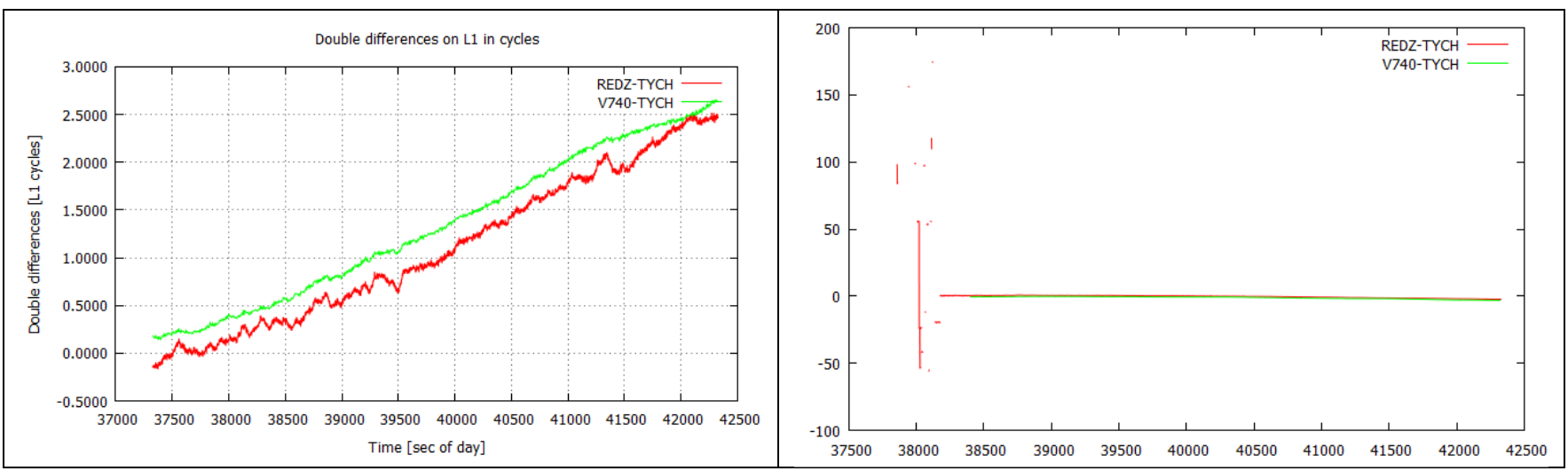

Fig. 3. Series of doubledifferences of type (2): a) data without cycle slips (PRN 2); b) data with cycle slips (PRN 5) 


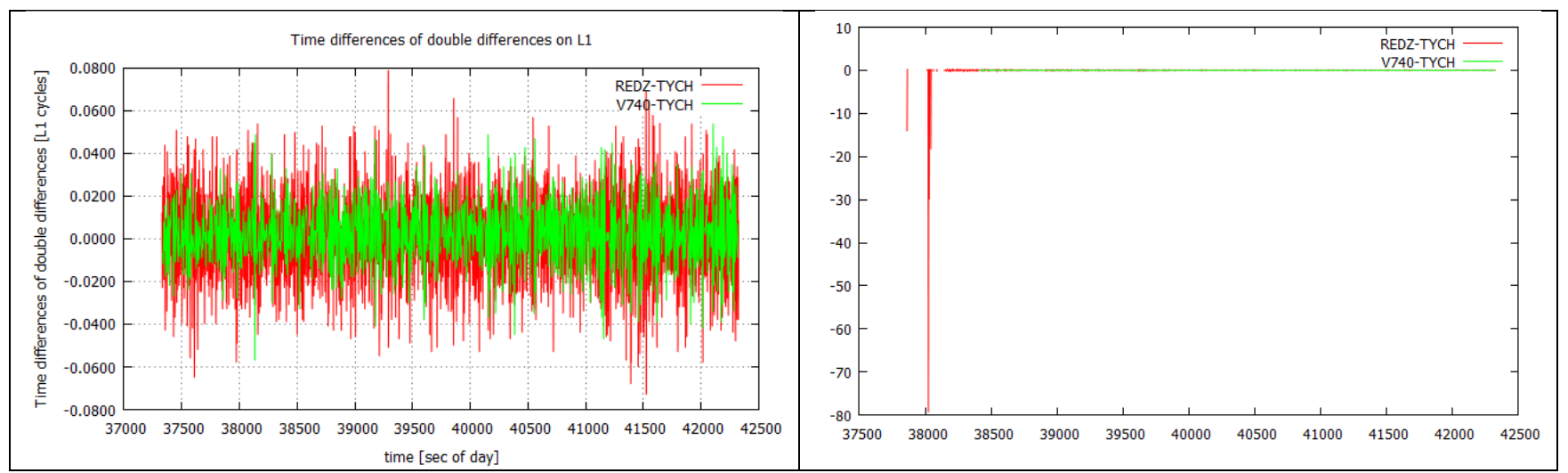

Fig. 4. Series of time differences of the double differences of type (2): a) data without cycle slips (PRN 2); b) data with cycle slips (PRN 5)

It can be seen that the double differences for vectors containing and not containing the VRSs have almost the same part of systematic influences, within the constant (responsible for the ambiguity part), but the data for REDZ-TYCH are more noisy than those for V740-TYCH (see Fig. 3a, 4a). Significant difference is observed when the cycle slips occurs (Fig. 3b, 4b). It seems that these cycle slips (they have been detected for data of 4 satellites at the vector REDZ-TYCH) are the actual reason of worse results obtained in AOS software.

\section{Conclusions}

On the basis of the performed computations, it can be stated that when the solution is good (fixed ambiguities, high accuracies estimated) the differences between vectors containing and not-containing VRSs are on the level of single millimeters. The biggest differences between the "with VRSs" and "without VRSs" have been observed in the case of bad solutions obtained in the AOS software for vectors between the REDZ physical reference station and two of the unknown physical stations. The solutions based on VRSs were significantly better. When obtaining results of poor quality from the software it is advised to check what solutions would be obtained for very close VRSs - in the case of the data studied in this paper, the results agreed with the reference coordinates within $\pm 15 \mathrm{~mm}$ for AOS and $\pm 25 \mathrm{~mm}$ for LGO. It is of no use to compute an unknown station from more than one VRSs located in close vicinity of it. If an adjustment would be performed for such network the accuracies obtained would be unreliably good. The studied VRS data gave better results for observations containing many cycle slips for the software which could not fix them. Other statistical differences between the double differenced data for the "with VRSs" and "without VRSs" have not been observed.

\section{References}

[1] Al-Shaery, A.; Lim, S.; Rizos, C. 2011. Investigation of Different Interpolation Models Used in Network-RTK for the Virtual Reference Station Technique, Journal of Global Positioning Systems 10(2): 136-148. http://dx.doi.org/10.5081/jgps.10.2.136

[2] Hu, G. R.; Khoo, H. S.; Goh, P. C.; Law, C. L. 2003. Development and assessment of GPS virtual reference stations for RTK positioning, Journal of Geodesy 77(5-6): 292-302. http://dx.doi.org/10.1007/s00190-003-0327-4

[3] Janssen, V. 2009. A comparison of the VRS and MAC principles for network RTK, in Proc. of the IGNSS 2009 Symposium, Surfers Paradise, Australia, 2009.

[4] Takac, F.; Lienhart, W. 2008. SmartRTK: A Novel Method Of Processing Standardised RTCM Network RTK Information For High Precision Positioning, in Proc. of ENC GNSS, Toulouse, France, 2008.

[5] Landau, H.; Vollath,U.; Chen, X. 2002. Virtual Reference Station Systems, Journal of Global Positioning Systems 1(2): 137-143. http://dx.doi.org/10.5081/jgps.1.2.137

[6] Hofmann-Wellenhof, B.; Lichtenegger, H.; Wasle, E. 2008. GNSS - Global Navigation Satellite Systems. Wien: Springer-Verlag. 516 p.

[7] Kisling, L. 2011. What is a virtual reference station and how does it work?, InsideGNSS 6(4): $28-31$.

[8] Wei, E.; Chai, H.; Liu, J.; An, Z. 2007. On the Generation Algorithm of VRS Virtual Observations, Geo-spatial Information Science 10(2): 91-95.

[9] Al-Shaery, A.; Lim, S.; Rizos, C. 2010. Functional Models of Ordinary Kriging for Medium Range Real-time Kinematic Positioning Based on the Virtual Reference Station Technique, in Proc. of the $23^{\text {rd }}$ International Technical Meeting of The Satellite Division of the Institute of Navigation (ION GNSS 2010), Portland, Oregon, 2010. 